Research Article

\title{
Gender-Specific Risk of Central Compartment Lymph Node Metastasis in Papillary Thyroid Carcinoma
}

\author{
Yushi Sun $\mathbb{D}^{1},{ }^{1}$ Hongjun Lv, ${ }^{1}$ Shaoqiang Zhang, ${ }^{2}$ Yanxia Bai, ${ }^{2}$ and Bingyin Shi $\mathbb{D}^{1}$ \\ ${ }^{1}$ Department of Endocrinology, First Affiliated Hospital of Xi'an Jiaotong University, Xi'an, Shaanxi, China \\ ${ }^{2}$ Department of Otolaryngology-Head and Neck Surgery, First Affiliated Hospital of Xi'an Jiaotong University, Xi'an, Shaanxi, China
}

Correspondence should be addressed to Bingyin Shi; shibyin1@126.com

Received 24 July 2017; Accepted 12 December 2017; Published 11 March 2018

Academic Editor: Claudio Casella

Copyright (c) 2018 Yushi Sun et al. This is an open access article distributed under the Creative Commons Attribution License, which permits unrestricted use, distribution, and reproduction in any medium, provided the original work is properly cited.

\begin{abstract}
Our aim was to evaluate the impact of gender on the predictive factors of central compartment lymph node metastasis (CLNM) in papillary thyroid carcinoma (PTC). A retrospective study of 590 patients treated for PTC was performed. Univariate and multivariate analyses showed that gender (female; $P=0.001$ ), age $(\geq 45 \mathrm{y} ; P<0.001$ ), tumor size $(>1 \mathrm{~cm} ; P<0.001)$, and multifocality $(P=0.004)$ were independent predictive factors of CLNM in PTC patients. Patients were divided into male group $(n=152)$ and female group $(n=438)$. Age $(\geq 45 \mathrm{y} ; P=0.001)$, T4 $(P=0.006)$ and multifocality $(P=0.024)$ were independent predictive risk factors of CLNM in male patients. As for female patients, age $(\geq 45 \mathrm{y} ; P<0.001)$, tumor size $(>1 \mathrm{~cm} ; P<0.001)$, multifocality $(P=0.002)$, and microcalcification $(P=0.027)$ were independently correlated with CLNM. The sensitivity of the multivariate model for predicting CLNM in male patients was $64.9 \%$, specificity was $82.9 \%$, and area under the ROC curve (AUC) was 0.764 . As for female patients, the sensitivity was $55.7 \%$, specificity was $77.9 \%$, and AUC was 0.73. This study showed that the predictive factors of CLNM indeed varied according to gender. To have a more accurate evaluation of CLNM, different predictive systems should be used for male and female patients.
\end{abstract}

\section{Introduction}

Papillary thyroid carcinoma (PTC), the most common type of thyroid cancer, constitutes $80 \%$ of all cases. The incidence of PTC increases rapidly and nearly doubles over the last 30 years [1]. PTC is usually considered as an indolent tumor and has a good prognosis. However, the cervical lymph node metastasis (LNM) especially central lymph node metastasis (CLNM) in PTC is very common with the incidence rate ranging from $45 \%-80 \%$ [2-5]. Several studies reported that LNM was associated with local tumor recurrence and poor prognosis of PTC [6-8]. However, there is substantial controversy regarding routine prophylactic central neck dissection in PTC patients because of the potential higher incidence of complications and uncertainty of improved oncological outcome $[9,10]$. Accurate evaluation of LNM prior to surgery is important for determining the appropriate extent of lymph node dissection.
Neck ultrasound (US) is the most valuable method for evaluation of primary thyroid cancer and nodal status [11-13]. It has been demonstrated that US could detect 70\% 93.8\% LNM in the lateral neck. However, the sensitivity of US for predicting CLNM in PTC is only 23\% 30.0\% $[11,14]$. Studies that attempted to investigate the predictive risk factors of CLNM in PTC patients were done recently and showed that some clinical factors such as age of onset, Hashimoto's thyroiditis (HT), thyroid-stimulating hormone (TSH), size of primary tumor, multifocality, and some other US features of the primary tumor were independently correlated with CLNM in PTC patients [3, 4, 15-17].

Gender is a prominent patient background parameter for PTC, and the clinicopathological features of PTC vary according to gender. It has been established that females have an earlier age of onset, but males tend to have a more aggressive disease with higher mortality [18-20]. Although previous studies investigated the factors predictive of CLNM 
in PTC, they did not distinguish between male and female patients. Our objective was to characterize and compare predictive factors of CLNM in PTC between the sexes. In this study, PTC patients were subclassified into male and female groups. The clinical features and their predictive value for CLNM were explored and compared between male and female patients.

\section{Methods}

A retrospective investigation was performed on PTC patients who had received initial thyroidectomy with at least one side central neck dissection at The First Affiliated Hospital of Xi'an Jiaotong University from January 2014 to June 2016. Central neck dissection was done routinely in our hospital for PTC patients in recent years. However, still, two percent of patients did not receive central neck dissection and were excluded from this study. Patients that had received preoperative $\mathrm{I}^{131}$ ablation or prior head and neck oncological surgery were excluded from this study. Those who had undergone TSH suppression therapy or antithyroid therapy before surgery were also excluded. Patients' age, gender, coexistence of HT (Hashimoto's thyroiditis), TSH (thyroid-stimulating hormone), T4 (tetraiodothyronine), T3 (triiodothyronine), TGAB (thyroglobulin antibody), TMAB (thyromicrosome antibody), ultrasonographic characteristics, and pathologic features were recorded.

A total of 590 patients were included in this study. The mean age was 42 years (range, 9-84 years). Coexistence of HT with PTC was confirmed by the postoperative pathological examination in $101(17.12 \%)$ patients. CLNM was histologically proven in 58.64\% (346/590) patients. Patients were divided into male group $(n=152)$ and female group ( $n=438)$. The clinical features of PTC were compared between male and female groups. Univariate and multivariate analyses were performed to explore and compare the independent predictive risk factors of CLNM in male and female groups.

The measurements of preoperative serum thyroid function and thyroid relative autoantibodies were done by radioimmunoassay. The normal range for $\mathrm{TSH}, \mathrm{T} 4$, and T3 was $0.25-5 \mu \mathrm{IU} / \mathrm{mL}, 4.2-13.5 \mu \mathrm{g} / \mathrm{dL}$, and $0.8-2.2 \mathrm{ng} / \mathrm{mL}$, respectively. The reference range of TGAB was $<30 \%$ and TMAB was $<20 \%$.

The results of preoperative neck US examinations were reviewed. The ultrasonographic characteristics of the suspicious thyroid nodules, including size, numbers (multifocal/unifocal), location (bilateral/unilateral), shape (regular/irregular), border (clear/obscure), echogenicity (hypoechoic/hyperechoic or isoechoic), calcification (noncalcification/microcalcification/coarse calcification), and degree of vascularization (none/low/middle/high), were recorded. Thyroid nodules that were diagnosed TI-RADS fourth or fifth grade by radiologists were defined as suspicious thyroid nodules in this study. The diameter of the largest suspicious thyroid nodule was used as tumor size for analysis. Lymph node showing one or more suspicious features (focal or diffuse hyperechogenicity, presence of internal calcification, cystic change, round shape, or chaotic vascularity) on US was regarded as clinical pathologic lymph nodes. Complete datasets were not available for all patients due to differences in reported parameters.

The statistical analysis was performed with SPSS (version 22.0). $P<0.05$ was considered statistically significant. Differences of single variables were tested with the chi-square test or unpaired nonparametric test (MannWhitney $U$ test). Multivariate analysis using logistic regression analysis was performed on the variables that showed $P<0.1$ in univariate analysis. Predictive value of those factors was measured using the area under the receiver operating characteristic (ROC) curve.

\section{Results}

3.1. Basic Clinical Features of PTC in Male Patients and Female Patients. 9.27\% (14/152) male PTC patients coexisted with HT which was significantly less than female patients $(P=0.003)$. Preoperative serum levels of TSH, TMAB, and TGAB were significantly lower in male patients than female patients $(P<0.05)$. A significant difference in nodular vascularization between male patients and female patients $(P=0.004)$ was noticed. There were no differences in age, preoperative T4 level, T3 level, nodular size, multifocality, bilaterality, nodular shape, border, internal echo, and calcification between male patients and female patients (Table 1).

\subsection{Comparison of CLNM according to Gender. CLNM was} histologically proven in 346 patients (58.64\%). Approximately $71.05 \%(108 / 152)$ male patients and $54.33 \%(238 /$ 438) female patients exhibited CLNM $(P<0.001)$. Compared with female PTC patients, male PTC patients were significantly associated with the number of metastatic central lymph nodes $(P<0.001)$ but not the number of removed central lymph nodes (Table 1 ).

3.3. Predictive Risk Factors of CLNM in PTC Patients. Univariate and multivariate analyses were used to detect the risk factors of CLNM in PTC patients. It was showed that gender (female; $P=0.001)$, age $(\geq 45 \mathrm{y} ; P<0.001)$, tumor size $(>1 \mathrm{~cm} ; P<0.001)$, and multifocality $(P=0.004)$ were independently correlated with CLNM in PTC patients (Tables 2 and 3).

3.4. Predictive Risk Factors of CLNM in Male Patients and Female Patients. Patients were divided into male group and female group. Univariate and multivariate analyses showed that the predictive factors of CLNM varied according to gender. In univariate analysis, age $(<45 \mathrm{y} / \geq 45 \mathrm{y})(P=0.005)$, T4 $(P=0.026)$, and nodular margin $(P=0.012)$ were significantly associated with high prevalence of CLNM in male PTC patients. As for female patients, age $(<45 \mathrm{y} / \geq 45 \mathrm{y})$, tumor size $(P<0.001)$, multifocality $(P=0.05)$, and the presence of microcalcifications on US $(P<0.001)$ were significantly associated with CLNM $(P<0.001)$ (Table 4$)$. Multivariate logistic regression analysis was performed to identify independent predictive risk factors of CLNM and showed that age $(\geq 45 y)(\mathrm{OR} 0.220 ; P=0.001), \mathrm{T} 4$ (OR 1.374; $P=0.006$ ), and multifocality (multifocal) 
TABLE 1: Clinicopathologic characteristic of female and male PTC patients.

\begin{tabular}{|c|c|c|c|}
\hline & Male $(n=152)$ & Female $(n=438)$ & $P$ value \\
\hline Age at diagnosis, $\mathrm{M}$ (range) & $41(9-78)$ & $43(12-84)$ & 0.265 \\
\hline Age $(<45 \mathrm{y} / \geq 45 \mathrm{y})$ & $\begin{array}{c}92 / 60 \\
60.5 \% / 39.5 \%\end{array}$ & $\begin{array}{c}244 / 194 \\
55.7 \% / 44.3 \%\end{array}$ & 0.301 \\
\hline Hashimoto's thyroiditis, $n(\%)$ & $14(9.27 \%)$ & $87(19.86 \%)$ & 0.003 \\
\hline $\mathrm{TSH}, \mu \mathrm{IU} / \mathrm{mL}, \mathrm{M}$ (range) & $1.63(0.07-8.27)$ & $2.02(0.07-72.8)$ & 0.017 \\
\hline $\mathrm{T} 4, \mu \mathrm{g} / \mathrm{dL}, \mathrm{M}$ (range) & $7.97(4.21-13.2)$ & $7.95(2-25.9)$ & 0.642 \\
\hline T3, ng/mL, M (range) & $1.43(0.52-2.55)$ & $1.33(0.5-4.57)$ & 0.098 \\
\hline TGAB, \%, M (range) & $3.76(2.45-53.6)$ & $4.55(1.82-63.7)$ & $<0.001$ \\
\hline TMAB, \%, M (range) & $3.08(1.69-39.8)$ & $3.54(1.43-44)$ & 0.001 \\
\hline \multicolumn{4}{|c|}{ Ultrasonographic characteristics of suspicious nodules } \\
\hline Tumor size $(\leqq 1 \mathrm{~cm} />1 \mathrm{~cm})$ & $\begin{array}{c}35 / 117 \\
23 \% / 77 \%\end{array}$ & $\begin{array}{c}104 / 334 \\
23.7 \% / 76.3 \%\end{array}$ & 0.488 \\
\hline Multifocal/unifocal & $\begin{array}{c}64 / 88 \\
42.1 \% / 57.9 \%\end{array}$ & $\begin{array}{c}195 / 243 \\
44.5 \% / 55.5 \%\end{array}$ & 0.754 \\
\hline Bilateral/unilateral & $\begin{array}{c}42 / 110 \\
27.6 \% / 72.4 \%\end{array}$ & $\begin{array}{c}134 / 304 \\
30.6 \% / 69.4 \%\end{array}$ & 0.515 \\
\hline Margin (regular/irregular) & $\begin{array}{c}60 / 84 \\
41.7 \% / 58.3 \%\end{array}$ & $\begin{array}{c}179 / 228 \\
44 \% / 56 \%\end{array}$ & 0.721 \\
\hline Border (clear/obscure) & $\begin{array}{c}75 / 71 \\
51.4 \% / 48.6 \%\end{array}$ & $\begin{array}{c}214 / 207 \\
50.8 \% / 49.2 \%\end{array}$ & 0.911 \\
\hline Hypoechoic/Hyper- or isoechoic calcification & $\begin{array}{c}139 / 10 \\
93.3 \% / 6.7 \%\end{array}$ & $\begin{array}{c}418 / 20 \\
95.4 \% / 4.6 \%\end{array}$ & 0.313 \\
\hline Non-/micro-/coarse calcification & $\begin{array}{c}27 / 105 / 20 \\
17.8 \% / 69.1 \% / 13.1 \%\end{array}$ & $\begin{array}{c}93 / 277 / 66 \\
21.3 \% / 63.5 \% / 15.1 \%\end{array}$ & 0.483 \\
\hline $\begin{array}{l}\text { Vascularization } \\
\text { None/low/middle/high }\end{array}$ & $\begin{array}{c}1 / 42 / 37 / 33 \\
0.8 \% / 37.2 \% / 32.7 \% / 29.2 \%\end{array}$ & $\begin{array}{c}25 / 132 / 118 / 55 \\
7.6 \% / 40 \% / 35.8 \% / 16.7 \%\end{array}$ & 0.004 \\
\hline \multicolumn{4}{|l|}{ Central lymph node metastasis } \\
\hline CLNM, $n(\%)$ & $108(71.05 \%)$ & $238(54.33 \%)$ & $<0.001$ \\
\hline Number of removed CLNs, M (range) & $5(0-27)$ & $6(0-41)$ & 0.139 \\
\hline Number of metastatic CLNS, M (range) & $2(0-20)$ & $1(0-19)$ & $<0.001$ \\
\hline
\end{tabular}

US: ultrasonography; CLNM: central lymph node metastases; NCLNM: central lymph node metastases negative; PTC: papillary thyroid cancer.

(OR 2.656; $P=0.024$ ) were independent predictors of CLNM in male PTC patients (Table 5). As for female PTC patients, age $(\geq 45 \mathrm{y})(\mathrm{OR} 0.289 ; P<0.001)$, tumor size $(>1 \mathrm{~cm})(\mathrm{OR} 2.761 ; P<0.001)$, multifocality (multifocal) (OR 1.966; $P=0.002$ ), and microcalcification (OR 1.822; $P=0.027$ ) were independently correlated with CLNM (Table 5).

3.5. ROC Analyses for Prediction of CLNM in PTC. Multivariate models were created and ROC analyses were performed to predict CLNM in male and female patients, respectively. The AUC was $76.4 \%$ for male and $73.0 \%$ for female patients $(P<0.001$; Figures $1(\mathrm{a})$ and $1(\mathrm{~b}))$. A cutoff point for prediction of CLNM was defined as a value $73.34 \%$ for male patients and $63.2 \%$ for female patients. The sensitivity of the multivariate model was $64.9 \%$, and specificity was $82.9 \%$ for prediction CLNM in male PTC patients. For female patients, the sensitivity of the model was $55.7 \%$ and specificity was $77.9 \%$ (Figure 1 ).

\section{Discussion}

Lymph node metastasis especially central lymph node metastasis is very common in PTC with the incidence rate ranging from 45\%-80\% [2-5]. Accurate evaluation of CLNM prior to surgery is important for determining appropriate extent of lymph node dissection. A considerable body of literature shows that male gender, age of onset $<45 \mathrm{y}$, tumor size $>81.0 \mathrm{~cm}$, and multifocality are associated with higher rate of CLNM in PTC [3, 4, 15-17]. Considering the impact of gender on the clinicopathological features of PTC, it is necessary to explore whether the predictive factors of CLNM differ by gender. This study confirmed the impact of gender on the clinical features of PTC and showed that the predictive factors of CLNM varied according to gender.

Gender is a prominent patient background parameter for PTC. Observed clinical and pathological differences between male and female PTC patients have been reported [18-20]. Previous studies showed that female PTC patients had an 
TABLE 2: Univariate analysis of the correlation between clinical factors of the primary tumor and rate of CLNM in PTC patients.

\begin{tabular}{|c|c|c|c|}
\hline & CLNM $(n=346)$ & NCLNM $(n=244)$ & $P$ \\
\hline Gender (male/female) & $\begin{array}{c}108 / 238 \\
31.2 \% / 68.8 \%\end{array}$ & $\begin{array}{c}44 / 200 \\
18 \% / 82 \%\end{array}$ & $<0.001$ \\
\hline Age at diagnosis, $\mathrm{M}$ (range) & $38(9-79)$ & $48(13-84)$ & $<0.001$ \\
\hline Age $(<45 \mathrm{y} / \geq 45 \mathrm{y})$ & $\begin{array}{c}239 / 107 \\
69.1 \% / 30.9 \%\end{array}$ & $\begin{array}{c}97 / 147 \\
39.8 \% / 60.2 \%\end{array}$ & $<0.001$ \\
\hline Hashimoto's thyroiditis, present/absent & $\begin{array}{c}53 / 293 \\
15.3 \% / 84.7 \%\end{array}$ & $\begin{array}{c}48 / 196 \\
19.7 \% / 80.3 \%\end{array}$ & 0.172 \\
\hline TSH, $\mu \mathrm{IU} / \mathrm{mL}, \mathrm{M}$ (range) & $1.99(0.07-26.5)$ & $1.79(0.07-28.3)$ & 0.676 \\
\hline T4, $\mu \mathrm{g} / \mathrm{dL}, \mathrm{M}$ (range) & $7.97(4.36-24.4)$ & $7.92(3.3-15.1)$ & 0.293 \\
\hline T3, ng/mL, M (range) & $1.35(0.5-2.55)$ & $1.35(0.63-2.28)$ & 0.415 \\
\hline TGAB, \%, M (range) & $4.3(1.98-62.6)$ & $4.27(1.82-63.7)$ & 0.671 \\
\hline TMAB, \%, M (range) & $3.48(1.53-41.7)$ & $3.32(1.69-44)$ & 0.489 \\
\hline \multicolumn{4}{|c|}{ Ultrasonographic characteristics of suspicious nodules } \\
\hline Tumor size $(\leqq 1 \mathrm{~cm} />1 \mathrm{~cm})$ & $\begin{array}{c}60 / 286 \\
17.3 \% / 82.7 \%\end{array}$ & $\begin{array}{c}79 / 165 \\
32.4 \% / 67.6 \%\end{array}$ & $<0.001$ \\
\hline Multifocal/unifocal & $\begin{array}{c}167 / 179 \\
48.3 \% / 51.7 \%\end{array}$ & $\begin{array}{c}92 / 152 \\
37.7 \% / 62.3 \%\end{array}$ & 0.005 \\
\hline Bilateral/unilateral & $\begin{array}{c}110 / 236 \\
31.8 \% / 68.2 \%\end{array}$ & $\begin{array}{c}66 / 178 \\
27 \% / 73 \%\end{array}$ & 0.235 \\
\hline Margin (regular/irregular) & $\begin{array}{c}129 / 194 \\
39.9 \% / 60.1 \%\end{array}$ & $\begin{array}{c}110 / 118 \\
48.2 \% / 51.8 \%\end{array}$ & 0.042 \\
\hline Border (clear/obscure) & $\begin{array}{c}163 / 168 \\
49.2 \% / 50.8 \%\end{array}$ & $\begin{array}{c}126 / 108 \\
53.8 \% / 46.2 \%\end{array}$ & 0.330 \\
\hline Hypoechoic/Hyper or isoechoic calcification & $\begin{array}{c}325 / 19 \\
94.5 \% / 5.5 \%\end{array}$ & $\begin{array}{c}232 / 11 \\
95.5 \% / 4.5 \%\end{array}$ & 0.670 \\
\hline Non-/micro-/coarse calcification & $\begin{array}{c}53 / 243 / 48 \\
15.4 \% / 70.6 \% / 14 \%\end{array}$ & $\begin{array}{c}66 / 140 / 38 \\
27 \% / 57.4 \% / 15.6 \%\end{array}$ & 0.001 \\
\hline $\begin{array}{l}\text { Vascularization } \\
\text { None/low/middle/high }\end{array}$ & $\begin{array}{c}12 / 99 / 87 / 59 \\
4.7 \% / 38.5 \% / 33.8 \% / 23 \%\end{array}$ & $\begin{array}{c}14 / 75 / 68 / 29 \\
7.5 \% / 40.3 \% / 36.6 \% / 15.6 \%\end{array}$ & 0.661 \\
\hline
\end{tabular}

CLNM: central lymph node metastases; NCLNM: central lymph node metastases negative; PTC: papillary thyroid cancer.

TABLe 3: Multivariate analysis of the correlation between clinical factors of the primary tumor and rate of CLNM in all PTC patients.

\begin{tabular}{lccc}
\hline Variables & OR & CI & $P$ \\
\hline Gender (female) & 0.475 & $0.304-0.744$ & 0.001 \\
Age $(\geq 45$ y) & 0.264 & $0.181-0.386$ & $<0.001$ \\
Margin (irregular) & 1.378 & $0.947-2.006$ & 0.094 \\
Tumor size ( $>1 \mathrm{~cm})$ & 2.51 & $1.61-3.915$ & $<0.001$ \\
Multifocality (multifocal) & 1.766 & $1.202-2.595$ & 0.004 \\
\hline
\end{tabular}

CLNM: central lymph node metastases.

earlier age of onset, but men tend to have a more aggressive disease with higher mortality $[21,22]$. In contradiction with previous reports, the current study showed no significant difference in age of onset, multifocality, and tumor size between male and female groups.

PTC has a strong propensity for lymph node metastasis. Nearly half of PTC has metastasized to the central lymph node at the time of diagnosis [2-5]. Preoperation risk of CLNM is important for deciding extent of surgery.
Recent studies focused on the predictive risk factors for CLNM have revealed that age of onset, size of tumor, and multifocality are independently associated with CLNM in PTC $[15,17,23]$. It has been established that age is negatively correlated with CLNM in PTC, and the risk of CLNM increases proportionally with the number of tumor foci $[15,24]$. Tumor size $>1$ was also reported to be a risk factor of CLNM in PTC $[25,26]$. Our study confirmed the predictive value of age and multifocality for CLNM in both male and female groups and showed that tumor size and microcalcification lost their predictive value for CLNM in male PTC patients.

TSH is a well-established risk factor of thyroid cancer. The association between TSH and CLNM was only observed by few of studies [3, 27]. The current study showed that although significant differences were observed in HT, TSH, TGAB, and TMAB between male and female groups, the predictive value of $\mathrm{HT}$, TSH, TGAB, and TMAB for CLNM was not differed by gender. They were not independent risk factors of CLNM in the two groups. Instead, T4 was proved to be an independent predictive risk factor of CLNM in male patients. 
TABLE 4: Univariate analysis of the correlation between clinical factors of the primary tumor and rate of CLNM in male and female PTC patients.

\begin{tabular}{|c|c|c|c|c|c|c|}
\hline & CLNM $(n=108)$ & $\begin{array}{c}\text { Male } \\
\text { NCLNM }(n=44)\end{array}$ & $P$ & CLNM $(n=238)$ & $\begin{array}{c}\text { Female } \\
\operatorname{NCLNM}(n=200)\end{array}$ & $P$ \\
\hline Age at diagnosis, $\mathrm{M}$ (range) & $37(9-78)$ & $47(26-66)$ & $<0.001$ & $38(12-79)$ & $47(13-84)$ & $<0.001$ \\
\hline Age $(<45 y / \geq 45 y)$ & $\begin{array}{c}73 / 35 \\
67.6 \% / 32.4 \%\end{array}$ & $\begin{array}{c}19 / 25 \\
43.2 \% / 56.8 \%\end{array}$ & 0.005 & $\begin{array}{c}166 / 72 \\
69.7 \% / 30.3 \%\end{array}$ & $\begin{array}{c}78 / 122 \\
39 \% / 61 \%\end{array}$ & $<0.001$ \\
\hline $\begin{array}{l}\text { Hashimoto's thyroiditis, } \\
\text { present/absent }\end{array}$ & $\begin{array}{c}10 / 98 \\
9.2 \% / 90.8 \%\end{array}$ & $\begin{array}{c}4 / 40 \\
9.1 \% / 90.9 \%\end{array}$ & 1.0 & $\begin{array}{c}43 / 195 \\
18.1 \% / 81.9 \%\end{array}$ & $\begin{array}{c}44 / 156 \\
22 \% / 78 \%\end{array}$ & 0.304 \\
\hline $\mathrm{TSH}, \mu \mathrm{IU} / \mathrm{mL}, \mathrm{M}$ (range) & $1.75(0.07-7.27)$ & $1.45(0.07-5.79)$ & 0.589 & $2.12(0.07-26.5)$ & $1.96(0.07-28.3)$ & 0.586 \\
\hline $\mathrm{T} 4, \mu \mathrm{g} / \mathrm{dL}, \mathrm{M}$ (range) & $8.34(4.68-13.2)$ & $7.86(5.25-12)$ & 0.026 & $8.03(4.36-24.4)$ & $8.17(3.3-15.1)$ & 0.892 \\
\hline T3, ng/mL, M (range) & $1.39(0.82-2.55)$ & $1.42(0.8-1.94)$ & 0.149 & $1.34(0.5-2.48)$ & $1.33(0.63-2.28)$ & 0.823 \\
\hline TGAB, $\%, M$ (range) & $3.84(2.53-51.3)$ & $3.51(2.45-43.1)$ & 0.423 & $4.79(1.98-62.6)$ & $4.39(1.82-63.7)$ & 0.408 \\
\hline TMAB, \%, M (Range) & $2.96(1.9-39.8)$ & $2.98(1.69-29.7)$ & 0.654 & $3.61(1.53-41.7)$ & $3.32(2.01-44)$ & 0.237 \\
\hline \multicolumn{7}{|c|}{$\begin{array}{l}\text { Ultrasonographic characteristics } \\
\text { of suspicious nodules }\end{array}$} \\
\hline Tumor size $(\leqq 1 \mathrm{~cm} />1 \mathrm{~cm})$ & $\begin{array}{c}22 / 86 \\
20.4 \% / 79.6 \%\end{array}$ & $\begin{array}{c}13 / 31 \\
29.5 \% / 70.5 \%\end{array}$ & 0.328 & $\begin{array}{c}38 / 200 \\
16 \% / 84 \%\end{array}$ & $\begin{array}{c}66 / 134 \\
33 \% / 67 \%\end{array}$ & $<0.001$ \\
\hline Multifocal/unifocal & $\begin{array}{c}50 / 58 \\
46.3 \% / 53.7 \%\end{array}$ & $\begin{array}{c}14 / 30 \\
31.8 \% / 68.2 \%\end{array}$ & 0.10 & $\begin{array}{c}117 / 121 \\
49.1 \% / 50.9 \%\end{array}$ & $\begin{array}{c}78 / 122 \\
39 \% / 61 \%\end{array}$ & 0.05 \\
\hline Bilateral/unilateral & $\begin{array}{c}32 / 76 \\
29.6 \% / 70.4 \%\end{array}$ & $\begin{array}{c}10 / 34 \\
22.7 \% / 77.3 \%\end{array}$ & 0.388 & $\begin{array}{c}78 / 160 \\
32.8 \% / 67.2 \%\end{array}$ & $\begin{array}{c}56 / 144 \\
28 \% / 72 \%\end{array}$ & 0.280 \\
\hline Margin (regular/irregular) & $\begin{array}{c}36 / 65 \\
35.6 \% / 64.4 \%\end{array}$ & $\begin{array}{c}24 / 19 \\
55.8 \% / 44.2 \%\end{array}$ & 0.012 & $\begin{array}{c}93 / 129 \\
41.9 \% / 58.1 \%\end{array}$ & $\begin{array}{c}86 / 99 \\
46.5 \% / 53.5 \%\end{array}$ & 0.352 \\
\hline Border (clear/obscure) & $\begin{array}{c}51 / 52 \\
49.5 \% / 50.5 \%\end{array}$ & $\begin{array}{c}24 / 17 \\
58.5 \% / 41.5 \%\end{array}$ & 0.488 & $\begin{array}{c}112 / 116 \\
49.1 \% / 50.9 \%\end{array}$ & $\begin{array}{c}102 / 91 \\
52.8 \% / 47.2 \%\end{array}$ & 0.446 \\
\hline $\begin{array}{l}\text { Hypoechoic/Hyper or } \\
\text { isoechoic calcification }\end{array}$ & $\begin{array}{c}98 / 8 \\
90.7 \% / 9.3 \%\end{array}$ & $\begin{array}{c}41 / 2 \\
95.3 \% / 4.7 \%\end{array}$ & 0.724 & $\begin{array}{c}227 / 11 \\
95.4 \% / 4.6 \%\end{array}$ & $\begin{array}{c}191 / 9 \\
95.5 \% / 4.5 \%\end{array}$ & 0.951 \\
\hline $\begin{array}{l}\text { Non-/micro-/coarse } \\
\text { calcification }\end{array}$ & $\begin{array}{c}18 / 73 / 17 \\
16.7 \% / 67.6 \% / 15.7 \%\end{array}$ & $\begin{array}{c}9 / 32 / 3 \\
20.4 \% / 72.7 \% / 6.9 \%\end{array}$ & 0.322 & $\begin{array}{c}35 / 170 / 31 \\
14.8 \% / 72 \% / 13.2 \%\end{array}$ & $\begin{array}{c}57 / 108 / 35 \\
28.5 \% / 54 \% / 17.5 \%\end{array}$ & $<0.001$ \\
\hline $\begin{array}{l}\text { Vascularization } \\
\text { None/low/middle/high }\end{array}$ & $\begin{array}{c}0 / 28 / 26 / 25 \\
0 / 35.4 \% / 32.9 \% / \\
31.7 \%\end{array}$ & $\begin{array}{c}1 / 14 / 11 / 8 \\
2.9 \% / 41.2 \% / \\
32.4 \% / 23.5 \%\end{array}$ & 0.434 & $\begin{array}{l}12 / 71 / 61 / 34 \\
6.7 \% / 39.9 \% / \\
34.3 \% / 19.1 \%\end{array}$ & $\begin{array}{l}13 / 61 / 57 / 21 \\
8.6 \% / 40.1 \% / \\
37.5 \% / 13.8 \%\end{array}$ & 0.579 \\
\hline
\end{tabular}

CLNM: central lymph node metastases; NCLNM: central lymph node metastases negative; PTC: papillary thyroid cancer.

TABLE 5: Multivariate analysis of the correlation between clinical factors of the primary tumor and rate of CLNM in male and female patients.

\begin{tabular}{lccc}
\hline Variables & OR & CI & $P$ \\
\hline Male group & & & \\
Age $(\geq 45$ y) & 0.220 & $0.093-0.519$ & 0.001 \\
T4, $\mu$ g/dL & 1.374 & $1.096-1.723$ & 0.006 \\
Multifocality (multifocal) & 2.656 & $1.135-6.215$ & 0.024 \\
Margin (irregular) & 1.241 & $0.549-2.807$ & 0.604 \\
Female group & & & \\
Age ( $\geq 45$ y) & 0.289 & $0.187-0.446$ & $<0.001$ \\
Tumor size (>1 cm) & 2.761 & $1.681-4.535$ & $<0.001$ \\
Multifocality (multifocal) & 1.966 & $1.284-3.010$ & 0.002 \\
Calcification & & & \\
Micro-/noncalcification & 1.822 & $1.069-3.103$ & 0.027 \\
Coarse/noncalcification & 1.427 & $0.712-2.858$ & 0.316 \\
\hline
\end{tabular}

CLNM: central lymph node metastases.
An evaluation based on the predictive risk factors is more effective than the one based on US features of cervical lymph nodes to predict the CLNM in PTC patients. Different multivariate models were created to calculate the probability of CLNM for male and female patients, respectively. ROC analysis was performed to predict CLNM in both groups (AUCs: $76.4 \%$ and $73.0 \%$, resp.). Compared with US of the cervical lymph node, the sensitivity of those models in predicting CLNM was much higher for male and female groups $(64.9 \%$ versus $34.26 \%$ and $55.7 \%$ versus $32.35 \%$, resp.), while the specificity of those models was a little lower than US (82.9\% versus $88.64 \%$ and $77.9 \%$ versus $89.5 \%$, resp.).

Several limitations of the present study should be noticed: First, this was a retrospective nonrandomized study. US was not performed by the same radiologist; interobserver variability among the radiologists may influence the results. Second, due to the difference in reported parameters by each radiologist, complete datasets were not available for all patients. Third, only PTC patients that received at least one side central neck dissection were 


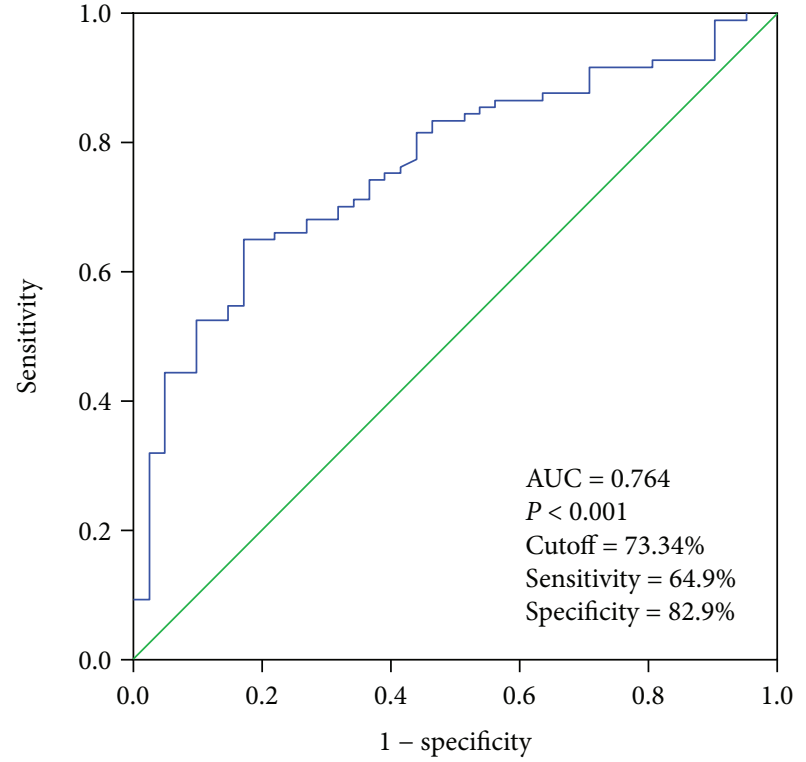

(a)

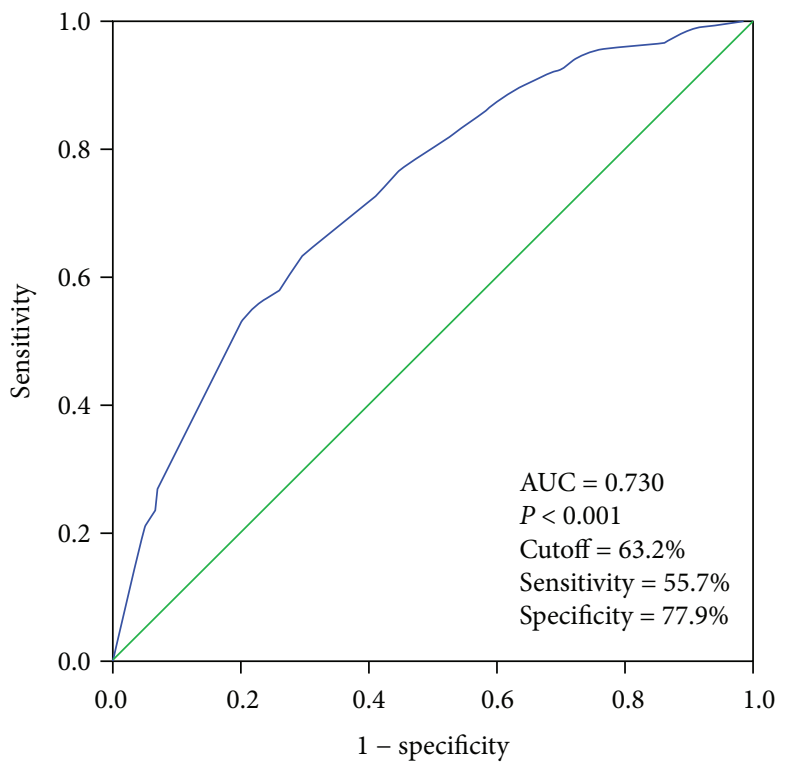

(b)

FIGURE 1: Receiver operating characteristic curve analyses for prediction of central lymph node metastases using the multivariate model. (a) Male papillary thyroid cancer patients. (b) Female papillary thyroid cancer patients.

included, and patients who had no LN dissection were excluded in this study, which has the potential selected bias associated with all retrospective analyses. Fourth, the number of patients especially the male PTC patients was relatively small. Further study with a large sample of patients is needed.

In conclusion, our study explored and confirmed the impact of gender on the predictive risk factors of CLNM in PTC for the first time. Our result suggested that to have a more accurate evaluation of CLNM, different predictive systems should be used for male and female patients.

\section{Conflicts of Interest}

The authors declare that they have no conflicts of interest.

\section{References}

[1] G. Pellegriti, F. Frasca, C. Regalbuto, S. Squatrito, and R. Vigneri, "Worldwide increasing incidence of thyroid cancer: update on epidemiology and risk factors," Journal of Cancer Epidemiology, vol. 2013, Article ID 965212, 10 pages, 2013.

[2] S. Noguchi, A. Noguchi, and N. Murakami, "Papillary carcinoma of the thyroid I. Developing pattern of metastasis," Cancer, vol. 26, no. 5, pp. 1053-1060, 1970.

[3] Y. Gao, N. Qu, L. Zhang, J.-y. Chen, and Q.-h. Ji, "Preoperative ultrasonography and serum thyroid-stimulating hormone on predicting central lymph node metastasis in thyroid nodules as or suspicious for papillary thyroid microcarcinoma," Tumour Biology, vol. 37, no. 6, pp. 7453-7459, 2016.

[4] A. al Afif, B. A. Williams, M. H. Rigby et al., "Multifocal papillary thyroid cancer increases the risk of central lymph node metastasis," Thyroid, vol. 25, no. 9, pp. 1008-1012, 2015.
[5] Y. Yang, C. Chen, Z. Chen et al., "Prediction of central compartment lymph node metastasis in papillary thyroid microcarcinoma," Clinical Endocrinology, vol. 81, no. 2, pp. 282-288, 2014.

[6] Y. D. Podnos, D. Smith, L. D. Wagman, and J. D. Ellenhorn, "The implication of lymph node metastasis on survival in patients with well-differentiated thyroid cancer," The American Surgeon, vol. 71, no. 9, pp. 731-734, 2005.

[7] V. Zaydfudim, I. D. Feurer, M. R. Griffin, and J. E. Phay, "The impact of lymph node involvement on survival in patients with papillary and follicular thyroid carcinoma," Surgery, vol. 144, no. 6, pp. 1070-1078, 2008.

[8] S.-M. Chow, S. C. K. Law, J. K. C. Chan, S.-K. Au, S. Yau, and W.-H. Lau, "Papillary microcarcinoma of the thyroidprognostic significance of lymph node metastasis and multifocality," Cancer, vol. 98, no. 1, pp. 31-40, 2003.

[9] C. J. Hughes, A. R. Shaha, J. P. Shah, and T. R. Loree, "Impact of lymph node metastasis in differentiated carcinoma of the thyroid: a matched-pair analysis," Head \& Neck, vol. 18, no. 2, pp. 127-132, 1996.

[10] Y. Ito, C. Tomoda, T. Uruno et al., "Clinical significance of metastasis to the central compartment from papillary microcarcinoma of the thyroid," World Journal of Surgery, vol. 30, no. 1, pp. 91-99, 2006.

[11] D. W. Lee, Y. B. Ji, E. S. Sung et al., "Roles of ultrasonography and computed tomography in the surgical management of cervical lymph node metastases in papillary thyroid carcinoma," European Journal of Surgical Oncology, vol. 39, no. 2, pp. 191-196, 2013.

[12] J. E. Ahn, J. H. Lee, J. S. Yi et al., "Diagnostic accuracy of CT and ultrasonography for evaluating metastatic cervical lymph nodes in patients with thyroid cancer," World Journal of Surgery, vol. 32, no. 7, pp. 1552-1558, 2008.

[13] S. Morita, K. Mizoguchi, M. Suzuki, and K. Iizuka, "The accuracy of ${ }^{18}[\mathrm{~F}]$-fluoro-2-deoxy-D-glucose-positron emission 
tomography/computed tomography, ultrasonography, and enhanced computed tomography alone in the preoperative diagnosis of cervical lymph node metastasis in patients with papillary thyroid carcinoma," World Journal of Surgery, vol. 34, no. 11, pp. 2564-2569, 2010.

[14] H. S. Hwang and L. A. Orloff, "Efficacy of preoperative neck ultrasound in the detection of cervical lymph node metastasis from thyroid cancer," The Laryngoscope, vol. 121, no. 3, pp. 487-491, 2011.

[15] F. Zhu, Y. B. Shen, F. Q. Li, Y. Fang, L. Hu, and Y. J. Wu, "The effects of Hashimoto thyroiditis on lymph node metastases in unifocal and multifocal papillary thyroid carcinoma: a retrospective Chinese Cohort Study," Medicine, vol. 95, no. 6, article e2674, 2016.

[16] N. Qu, L. Zhang, D.-z. Lin, Q.-h. Ji, Y.-x. Zhu, and Y. Wang, "The impact of coexistent Hashimoto's thyroiditis on lymph node metastasis and prognosis in papillary thyroid microcarcinoma," Tumour Biology, vol. 37, no. 6, pp. 7685-7692, 2016.

[17] Q. Wu, Y. Li, Y. Wang, and B. Hu, "Sonographic features of primary tumor as independent predictive factors for lymph node metastasis in papillary thyroid carcinoma," Clinical and Translational Oncology, vol. 17, no. 10, pp. 830-834, 2015.

[18] B. A. Kilfoy, S. S. Devesa, M. H. Ward et al., "Gender is an age-specific effect modifier for papillary cancers of the thyroid gland," Cancer Epidemiology, Biomarkers \& Prevention, vol. 18, no. 4, pp. 1092-1100, 2009.

[19] R. Rahbari, L. Zhang, and E. Kebebew, “Thyroid cancer gender disparity," Future Oncology, vol. 6, no. 11, pp. 1771-1779, 2010.

[20] F. D. Gilliland, W. C. Hunt, D. M. Morris, and C. R. Key, "Prognostic factors for thyroid carcinoma. A populationbased study of 15,698 cases from the Surveillance, Epidemiology and End Results (SEER) program 1973-1991," Cancer, vol. 79, no. 3, pp. 564-573, 1997.

[21] N. Qu, L. Zhang, Q.-h. Ji et al., "Number of tumor foci predicts prognosis in papillary thyroid cancer," BMC Cancer, vol. 14, no. $1,2014$.

[22] S. F. Kuo, S. F. Lin, T. C. Chao, C. Hsueh, K. J. Lin, and J. D. Lin, "Prognosis of multifocal papillary thyroid carcinoma," International Journal of Endocrinology, vol. 2013, Article ID 809382, 6 pages, 2013.

[23] Y. Lee, Y.-S. Lim, J.-C. Lee et al., "Ultrasonographic findings relating to lymph node metastasis in single micropapillary thyroid cancer," World Journal of Surgical Oncology, vol. 12, no. 1, p. 273, 2014.

[24] S. Siddiqui, M. G. White, T. Antic et al., "Clinical and pathologic predictors of lymph node metastasis and recurrence in papillary thyroid microcarcinoma," Thyroid, vol. 26, no. 6, pp. 807-815, 2016.

[25] J. P. Park, J. L. Roh, J. H. Lee et al., "Risk factors for central neck lymph node metastasis of clinically noninvasive, nodenegative papillary thyroid microcarcinoma," The American Journal of Surgery, vol. 208, no. 3, pp. 412-418, 2014.

[26] A. Konturek, M. Barczynski, W. Nowak, and W. Wierzchowski, "Risk of lymph node metastases in multifocal papillary thyroid cancer associated with Hashimoto's thyroiditis," Langenbeck's Archives of Surgery, vol. 399, no. 2, pp. 229-236, 2014.

[27] C. Li, W. Yu, J. Fan et al., "Thyroid functional parameters and correlative autoantibodies as prognostic factors for differentiated thyroid cancers," Oncotarget, vol. 7, no. 31, pp. 49930-49938, 2016. 


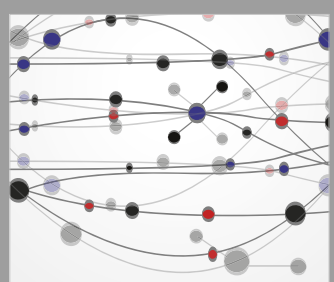

The Scientific World Journal
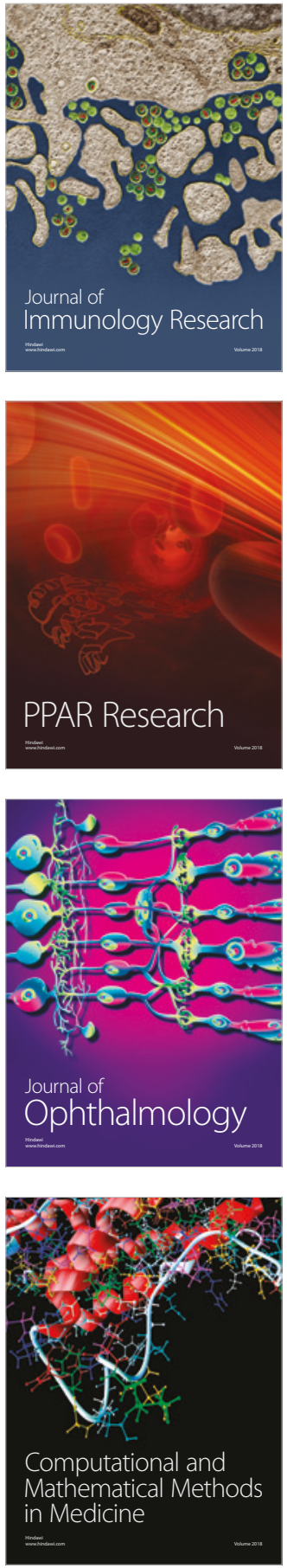

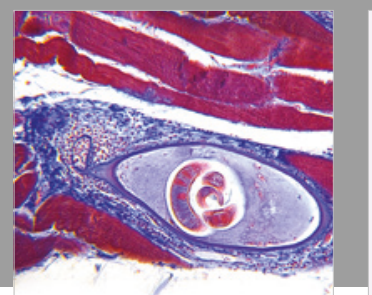

Gastroenterology Research and Practice

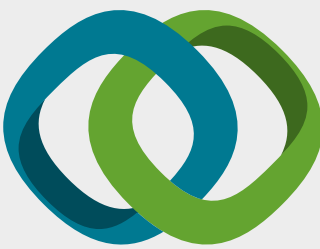

\section{Hindawi}

Submit your manuscripts at

www.hindawi.com
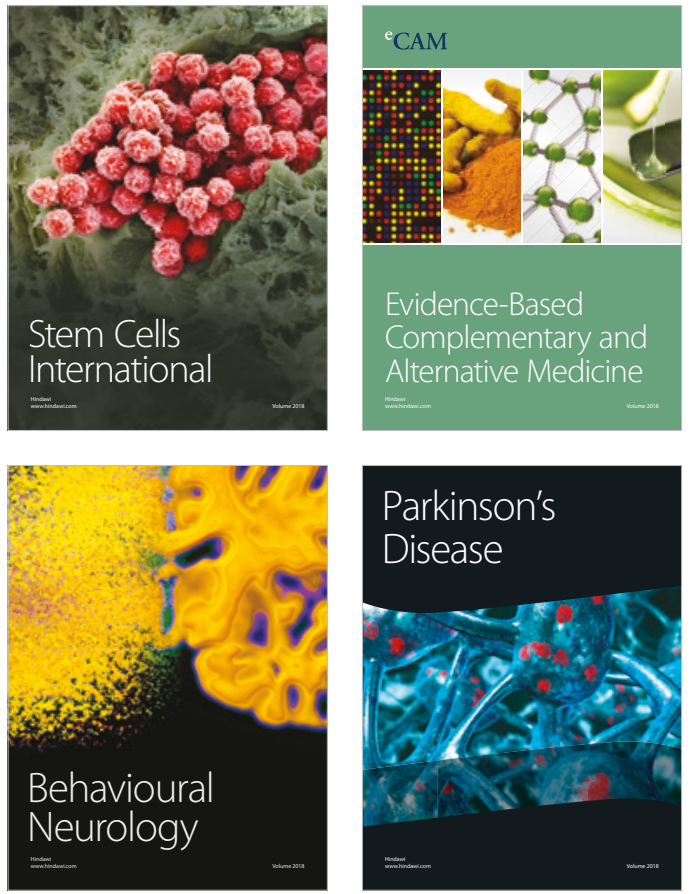

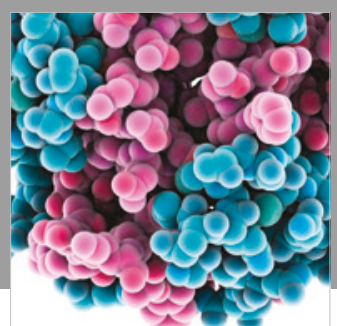

ournal of

Diabetes Research

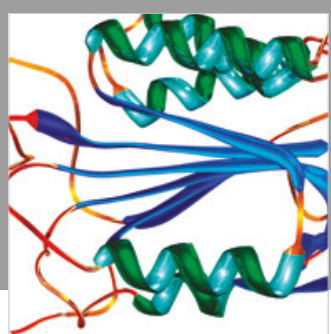

Disease Markers
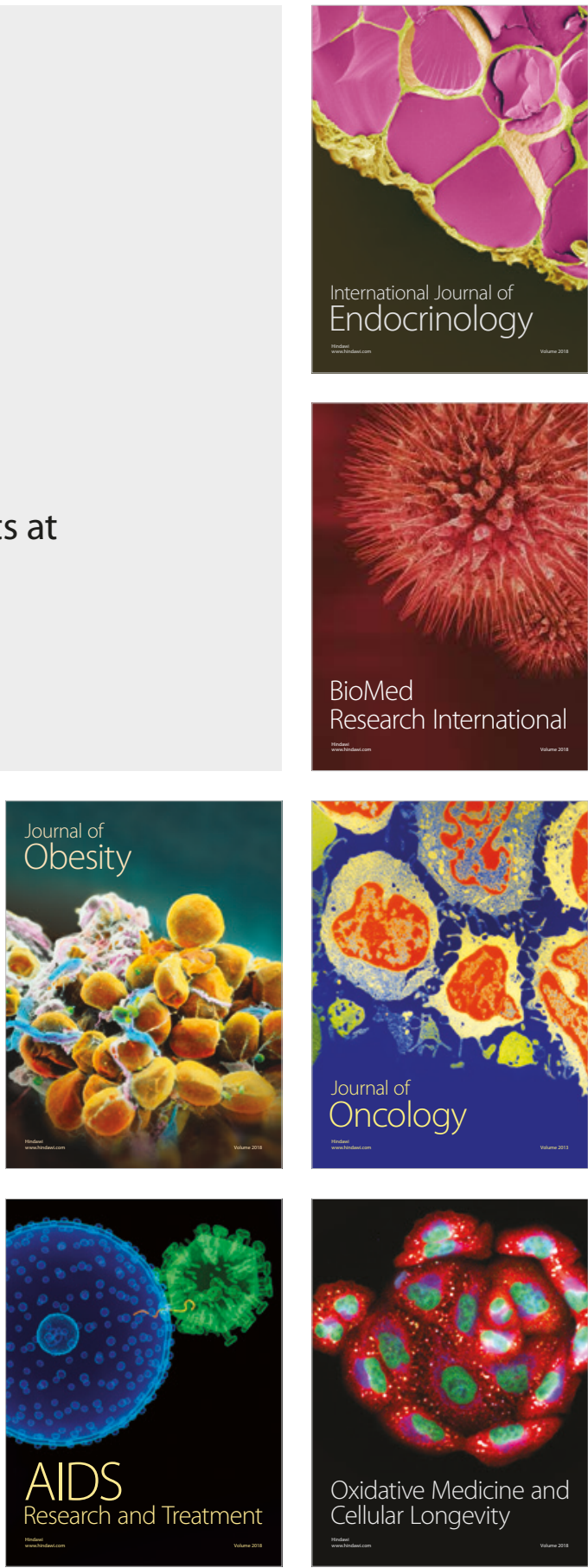